\title{
EMA JA ISA RAHVAKEELSED NIMETUSED
}

\section{VILJA OJA}

Annotatsioon. Artikkel käsitleb peamiselt eesti murdesõnu, mida XX sajandil kasutati ema ja isa sünonüümidena pereringis ning sugulaste ja kogukonna omavahelises suhtluses. Vanu ema kutsumise nimetusi nänn ja nann, eit ja äidi, ääde jms ning isa kutsumise nimetusi tätä, ät ja att, mis olid eelistatud üsna kindlatel murdealadel, hakati XX sajandi 1. poolel asendama uuematega. Üsna laialt oli levinud emanimetus memm ja isanimetus taat. Kohati kasutati lastekeelseid sõnu tata, tätä 'isa' ja valdavalt Saaremaal sõna emm 'ema'. Saksa laene mamma ja papa ning mammi ja papi peeti umbes XX sajandi keskpaigani paljudes kohtades uueks ja peenutsevaks. Tähendusmuutused, kus ema- ja isanimetustest said vanavanemaid ning üldisemalt perenaist või -meest ja vana naist või meest tähistavad sõnad, on seotud uute ema- ja isanimetuste kasutuselevõtuga. Eesti keeles kohtame sama struktuuriga sõnu nagu paljudes indoeuroopa ja turgi keeltes: isanimetustes esinevad sageli klusiilist $p(b)$ või $t(d)$ ja vokaalist $a$ koosnevad silbid ning emanimetustes on klusiili asemel nasaal $m$ või $n$. Osa eesti sõnu on laenud, kuid kõigi päritolu pole selge. 1960-ndatel hakkas tasapisi populaarsust võitma eesti kohalik hoidjakeelne emme ja pisut hiljem ka issi. Tänaseks on neist kujunenud peaaegu üldkeelsed hellitusnimetused.

Võtmesõnad: lastevanemate nimetused, tähendusmuutused, laste- ja hoidjakeel, eesti murded

\section{Sissejuhatus}

Eesti keeles XX sajandi 1. poolel ja varem lastevanemaid tähistanud sõnu on käsitlenud Albert (Andrus) Saareste (1924) ning koos teiste soome-ugri keelte sugulussõnadega Ruben Erik Nirvi (1952) ja Eduard Vääri (2013, käsikiri 1953). XX sajandi lõpukümnenditel kerkis teema Euroopa keelte atlase (ALE) koostamisel uuesti päevakorrale. Atlase küsitluskava järgi tuli murdekeelseid vanemate ja vanavanemate nimetusi koguda kahes jaos: 1) ametlikud ehk nn formaalsed: 'isa' (ALE küsimus 455), 'ema' (457), 'vanaisa (465), 'vanaema' (467), ja 2) mitteametlikud ehk kutsumisnimetused: 'isa' (456), 'ema' (458), 'vanaisa' (466), 'vanaema' (468) (ALE 
1976: 78-81). Eesti materjali esitades kaasati murdearhiivis (EMSUKA) leiduvad nimetused, mistõttu vastustes kajastuvad ka XX sajandi 1. poolel talletatud sõnad. Euroopa keelte atlases ilmusid artiklid ja kaardid isa, vanaisa ja vanaema ametlike nimetuste kohta (ALE 2014; Brietz 2014). Sugulussõnu on kaardistatud ja kommenteeritud ka läänemeresoome keeleatlases (ALFE), kus ema ja isa tähistavaid eesti sõnu esindavad samuti murdealati levinud ametlikud üldnimetused, kuid isanimetuste kaardile on lisatud ka kutsumisnimetusi. Soome-ugri keelte sugulussõnade päritolu kohta on ilmunud Huno Rätsepa ülevaatlik artikkel ajakirjas Oma Keel (Rätsep 2009).

Kõigil eesti murdealadel on kasutatud kirjakeelsetega sarnaseid sõnu ema ja isa või kohalikke häälikuvariante, nagu emä ja isä, Lei jema, Kra jemä, Võn V imä ning eL esä, eśä, Lei Lut Kra (j)esa, jeśa, jesä või jeśä (täpsemalt vt EMS I: 722 jj, 819, 1059-1060). Saareste, nagu ka hilisemate uurijate järelduste kohaselt on soome-ugri taustaga sõnade ema ja isa variandid esialgu olnud stiili poolest kõige neutraalsemad lastevanemate nimetused (Saareste 1924: 120, 123). Nende kõrval olid käibel teised sõnad, mida eelistati suhtlemisel pere ja sugulaste ringis või mingis muus kogukonnas, kuid sageli on neidki kasutatud mingil murdealal põhiliste üldnimetustena. Osa selliseid sõnu on jõudnud keeleatlastesse kui ametlikud murdenimetused, teine osa mitte (ALE 2014; ALFE) ${ }^{1}$. Sõnu isa ja ema on seni avaldatud uurimustes ammendavalt analüüsitud, mistõttu alljärgnevalt neile otseselt tähelepanu ei pöörata. Ehkki ülalmainitud kolmes uurimuses on käsitletud ka enamikku murdelistest kutsumisnimetustest, näitab hiljem lisandunud materjal selles vallas toimunud muutusi. Seetõttu tutvustatakse lühidalt nende varasemat esinemust, lisades uuemat teavet. Murdekeelsetes kirjetes järgitakse „Eesti murrete sõnaraamatu“ transkriptsiooni ning murdealade ja murrakute lühendeid (vt EMS I: 29-32). Mõnikord on murdenäitele lisatud kogumise aasta.

\section{Emanimetused}

Mõlemas atlases (ALE ja ALFE) on esitatud ema neutraalse üldnimetusena eesti murretest sõnad ema (emä, imä jt variandid) ja nann (nänn) (vt ALFE: 227-231). ALFE-s on ema üldnimetusena registreeritud ema

\footnotetext{
Sõnade levikukaardid siinses artiklis ei piirdu ALE ja ALFE kaardistuspunktidega, vaid esitavad kogu teadaoleva murdematerjali tähendustes 'isa' ja 'ema'.
} 
(+ variandid) kõigis kaardistuspunktides ja nann g nanne Risti murrakus ning nänn g nänni nänne Muhu murrakus. Tegelikult on sõna nänn murretes tunduvalt laiemalt levinud (VMS: 122; Pajusalu 2010: 332-333). Eesti murdesõnavara kogu andmeil on ema kutsutud nänn või näńn g nänna (näńnä), nänne (näńne), nänni (nänni) Mulgi murdes ja selle naabruses nii Põhja-Viljandimaal ja Pärnumaal Saarde murrakus kui ka Tartu ja Võru murde lääneosas ning lisaks Läänemaa lõunaosas ja saartel Muhu, Pöide ja Emmaste murrakus. Variant nenn g nenne oli emanimetus idamurdes ja nenne vadja keeles (kaart 1; EMSUKA; VKS: 802). Sama sõnaga on nimetatud vanaema, muid sugulasi või vana naist, kuid neid tähendusi pole juuresoleval levikukaardil arvesse võetud. Eesti keeles ja teistes läänemeresoome keeltes on nänn jms tähistanud ühtlasi mõistet 'emarind, nisa', mida peetaksegi algupäraseks (Saareste 1924: 122-123; Nirvi 1952: 119; SSA 2: 252; EES: 328; Vääri 2013: 52). Teiselt poolt esineb samasugune emanimetus rootsi murretes, sh eestirootsi murdes nann pl nannar, soomerootsi Nylandi murdes ja Åbolandi murrakutes (Karleby, Hitis) nanna või nännå ning soome murretes: Ida-Soome lõunarannikul ja saartel nanna, nannakka ning Häme murdes nenna (Ariste 1933: 81; Danell 1951: 287; ALFE: 227, 230; OFSF 4: 513, 592). Seetõttu on eesti ja soome sõna (eriti tähenduse 'ema') puhul oletatud laenulisust või vähemalt rootsi mõju (Nirvi 1952: 118; SKES: 365; SSA 2: 204). Saareste arvates (1924: 122-123) on ees- ja tagavokaalne tüvi erineva päritoluga - nänn on vana läänemeresoome sõna ja nann hilisem eestirootsi laen, kuid XX sajandi algul on mõlemaid tarvitatud lastekeeles afektiivse emanimetusena.

Neutraalsele üldnimetusele ema kõige lähemaks pidas Saareste (1924: 123) hellitava alatooniga sõna eit. Atlaste materjalis liigitati eit eesti keeles kutsumisnimetuseks. Tähenduses 'ema' on eit g eide, eede, eede murdesõnavara kogus registreeritud peamiselt põhjaeesti murde läänepoolse osa murrakutest ning $\ddot{a}$ - $(a-)$ algulised variandid Võru murdest: Plv äit, VLä äide, äidi, VId ääde, Kra aad́e g aadõ (EMS I: 44, 636-637; EMSUKA; Pajusalu 2010: 330-331). Võrumurdelisel sõnal oli samuti hellitav nüanss, nt Har (1939) tuu äide nimi oĺl õks kaĺlip viil ku imä nimi. Võru murdes on nõnda nimetatud ka vanaema (vt osa 5). Eesti sõnad pärinevad samast germaani tüvest nagu soome äiti g äidin, vrd gooti aipei, küsks eide 'ema' (Saareste 1924: 121; Nirvi 1952: 113; SSA 3: 495; EES: 60; Vääri 2013: 49). Sõnu eit, äidi, ääde ning nann, nänn, nenne analüüsinud, kinnitab Karl Pajusalu (2010), et need kuuluvad läänemeresoome vanasse sõnavarakihti, 
reastades vokaalialgulised sõnad kõige varasemateks emanimetusteks ning $n$-algulised neist järgmiseks.

Emanimetust emm g emme on rohkesti tarvitatud Saaremaal, vähem Muhus ja Emmastes, seevastu Mandri-Eesti murrakutest on üksikteateid, mõnele on lisatud märkus „harva“ või „naljatamisi“" (kaart 2; EMS I: 737; EMSUKA). Seda peetakse sõnast ema mugandatud lastekeelseks variandiks (Saareste 1924: 123; Vääri 2013: 52). Nimetavalise emme kohta on murdearhiivis üksikud teated Saaremaalt, Emmastest ja kolmest keskmurde murrakust, osa neist suhteliselt hilised (registreeritud 1968. ja 1978. aastal). Keskmurdest kirja pandud näited illustreerivad ilmselgelt lapsele suunatud täiskasvanukõnet ehk hoidjakeelt (vt osa 6).

Ema on nimetatud memmeks peamiselt Mandri-Eesti murretes, kõige rohkem Tartumaal ja selle naabruses (kaart 2). Sõna memm g memme on eesti keeles alamsaksa laen < asks memm(e) 1stk 'ema' (Ariste 1937: 136; Ariste 2010: 205; EES: 280). Uuem nimetus mamma (R 'mamma) esineb hajalevikuga üle Eesti (kaart 5; EMS V: 936). Seda on peetud eesti keeles rootsi või saksa laenuks (Saareste 1924: 123; Rätsep 2009: 31; EES: 274). Leviku põhjal võib oletada pigem saksa päritolu, ent ei saa välistada ka mitmepoolset laenamist. Kõrvuti nimetusega mamma esineb $i$-lõpuline variant mammi. Vormiliselt võiks see olla deminutiivne tuletis eelmisest, kuid keelenäidete põhjal on tegemist võrdväärsete sünonüümidega. Sõnu mamma ja mammi on üldiselt peetud peenutsevaks ehk saksikuks, nt Trm peenemad rahvas 'ôikavad mammi; Pal ema oli arilik nimi, mamma oli peenem (EMS V: 936). Mõlemat nimetust kasutati XX sajandi algupoolel enam noorte seas, linnakeskkonnas, haritud peredes ja härrasrahva teenijate poolt (Saareste 1924: 123; EMSUKA). Samasugune positsioon oli paljudes soome murretes rootsi keelest laenatud emanimetusel mamma ning selle variantidel mammi, mammo jt (ALFE: 230; SMSA). Soome, karjala, vepsa, isuri ja vadja murretest on mamma jms levik kuvatud ALFE kaardil, kust eesti vastete levik jäi kahjuks nimetuste ametlikeks ja mitteametlikeks liigitamise tagajärjel välja (ALFE: 227). Võrreldes sõnade mamma ja memm kasutust, torkab silma tähenduslik erinevus, nimelt sõna memm ei peeta tavaliselt peenutsevaks ning seda on rohkem kasutatud hellitusnimena.

Eelmistega ühisest algtüvest on lähtunud venekeelne emanimetus māma (мама), millest on laenatud Ida-Võru murdesõna maama 'ema' (EEW: 1471; Must 2000: 188; EMS V: 837). Idapoolsetes läänemeresoome 


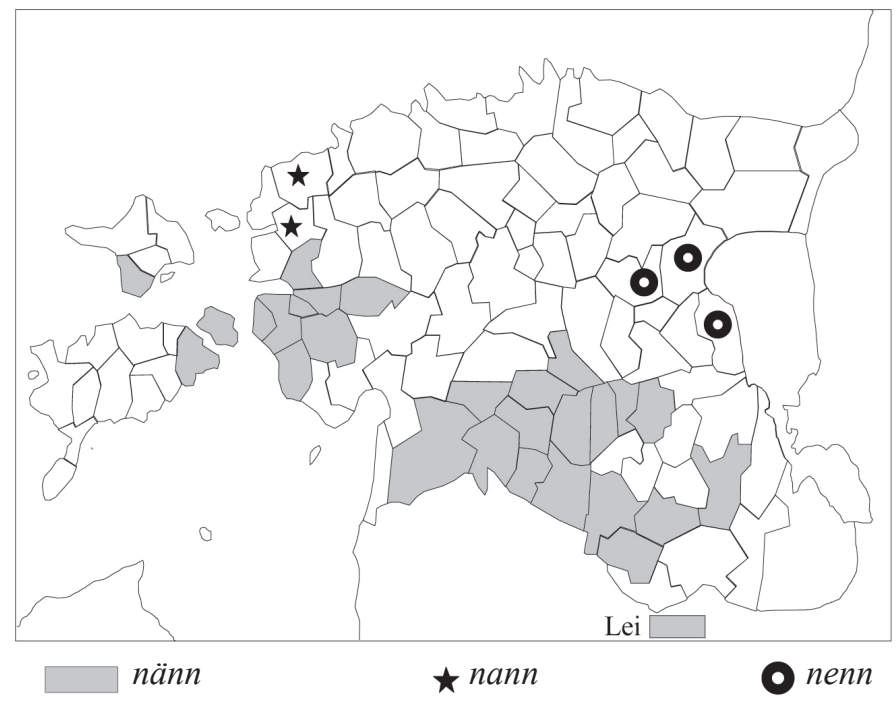

Kaart 1. Emanimetused nänn, nann ja nenn

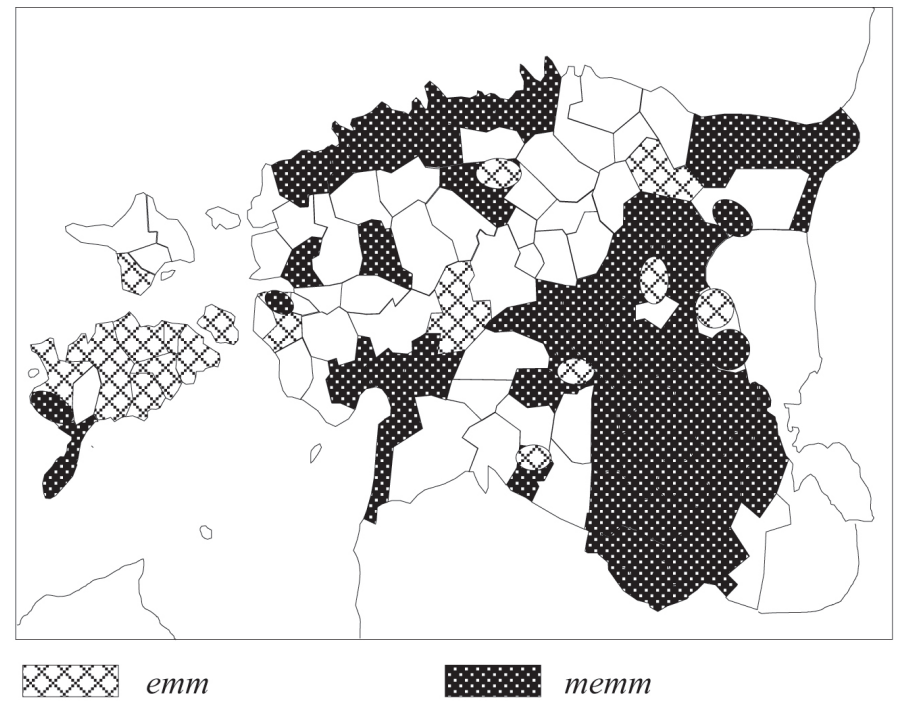

Kaart 2. Emanimetusi eesti murretes 
keeltes näivad analoogilised vene laenud (isuri, vadja māma, vepsa mam, mamō, karjala moamo, muamo jt) vähemalt kohati olevat üsna vanad, sest neid kohtab isegi rahvalauludes ema sünonüümina (Nirvi 1952: 120-121). Eesti õigekeelsussõnaraamatus esinevad emanimetusena mamma ning sellest moodustatud argikeelne mamps (ÕS 2013: 521). Muudest laennimetustest võiks veel mainida Risti murrakus ema tähistanud sõna moor ( $<$ rts mor 'ema', erts 'ema, naine, abikaasa') ja mitmel murdealal kasutatud sõna mutter < sks Mutter 'ema' või mutt, muti < sks Mutti'emake, memm' (Ariste 1933: 79-80; EES: 284, 290). Sõnu moor, mutt (muti) ja mutter tarvitatakse murretes laiemalt peamiselt tähenduses '(vanem) naine, eit; abikaasa' (EMS VI: 125, 234, 235).

\section{Isanimetused}

Üldnimetuse isa peamised sünonüümid eesti murretes on ätt või att, taat, tata, tätä ja papa. Enim on tarvitatud nimetust taat (-t; -ae-, -ua-), g taadi (eL ka taade) (kaart 3).

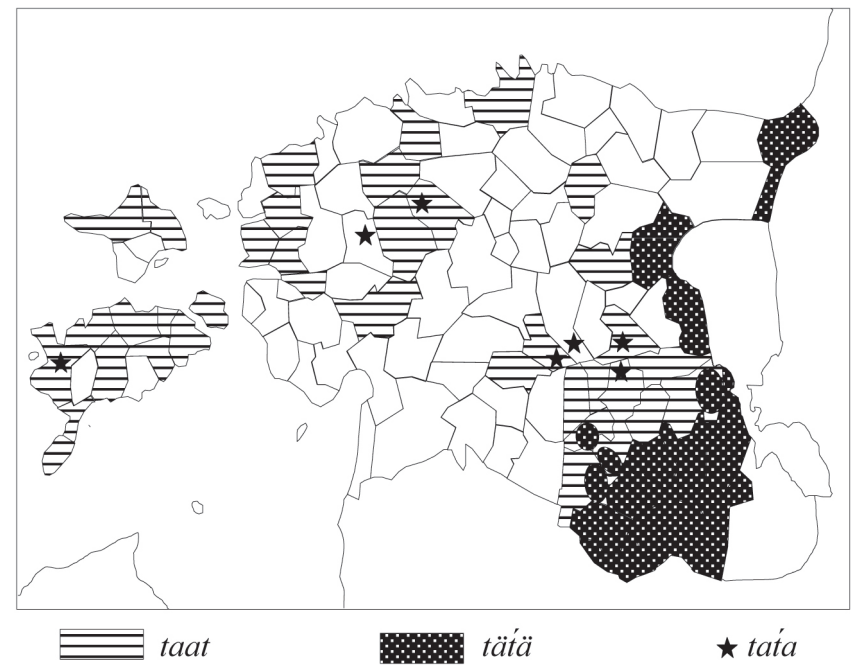

Kaart 3. Isanimetused taat, tätä ja tata

Selle vasted teistes läänemeresoome keeltes on eri tüvevokaalidega: isuri, vadja ja vepsa keeles - $a$, karjala ja soome murretes - $a$ või - $o$, liivi keeles ja mõnes soome murdes $-i$, ning neid on käsitletud ka läänemeresoome 
keeleatlases ametlike isanimetuste artiklis (ALFE: 191-192). Eesti murretest on registreeritud lastekeelseid $a$-tüvelisi variante, nagu Vai 'taata, Khn Muh taeda, Khk Jaa Pöi taida, ning laiemal alal levinud täta või tat́a (EMSUKA). Sõna taat ja selle variantide aluseks on üldiselt peetud lastekeelset läänemeresoome omatüve, ent osa neist on tõenäoliselt vene laenud, vrd vn tata, tjatja (SSA 3: 249-250; ALFE: 194; EES: 506). Euroopa keeltes on $t a$ - või te-tüvega isanimetused laialt levinud, sh meie naabritel balti ja slaavi keeltes (ALE 2014: kaart 85; Brietz 2014: 127-128).

Nimetusega att (Mih att) g ati, ati on kutsutud isa peamiselt läänemurde alal (kaart 4). Eesvokaalne ätt (g äti, M äti) või ätt g äte oli tavaline Viljandimaal ja selle naabruses, kuid esines paiguti ka lääne pool. Kohalike jaoks on siin selge vahe, nagu ütles üks Saarde keelejuht: taga Pärnu oli att, siin on ätt. Teine Saarde elanik seletab, et ätt ja papa ja taat, egas vallas oli esi 'moodu.

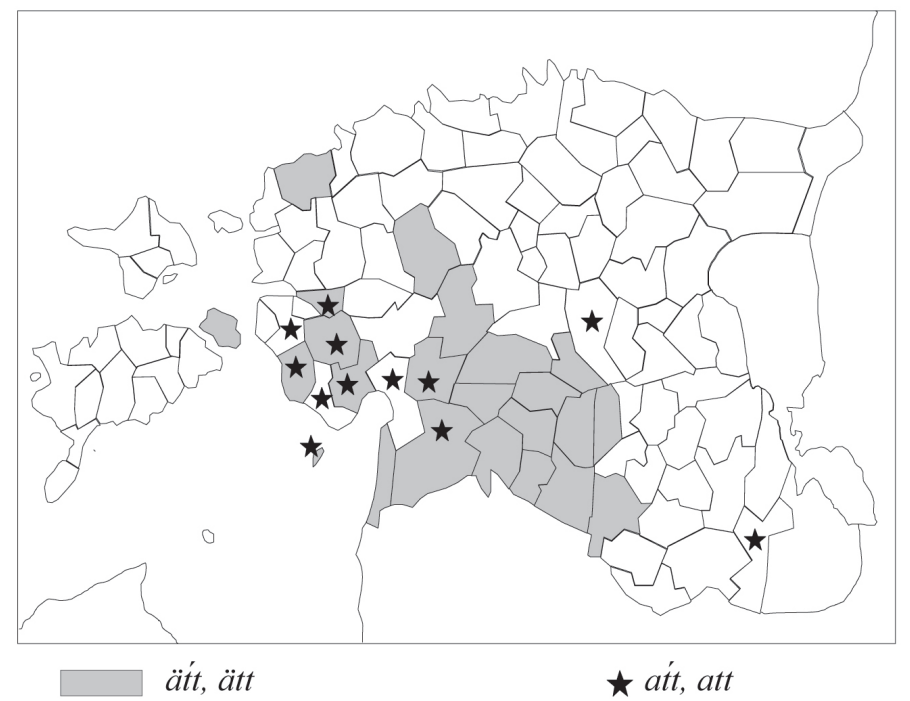

Kaart 4. Isanimetused ätt ja att

Sõnu att ja ätt on käsitatud lastekeelel põhinevate häälikuvariantidena, kuid on viidatud ka sarnase tüvega nimetustele mordva, ungari, saksa jt keeltes (SSA 1: 88; SSA 3: 499-500; ALFE: 191-194; Rätsep 2009: 31). Saareste arvates (1924: 121-122) võiksid need pärineda algläänemeresoome või isegi varasemast ühissõnavarast, vrd ka isuri ätti, vadja ätä ning soome 
Tütarsaare ätti, ättä (ALFE: 193). Teiselt poolt võib eesti sõna olla varane saksa laen, vrd küsks atta, murretes ka ätte 'isa' ja sks Att(e), deminutiiv Äti 'isa, vanaisa' (Lehmann 1986: 46; Kluge 2002: 69). Euroopa keelte atlase järgi on at-algulised isa- ja vanaisanimetused väga tavalised slaavi ja turgi keelte murretes ning lapi keeltes, mujal harvem (ALE 2014: kaart 85; Brietz 2014: 126-127, 154; Räsänen 1969: 31). See ei peegelda muidugi sõna tegelikku kasutust, kuna ALE vahendab ainult ametlikke murdenimetusi (ALE 1976: küsimused 455, 465).

Tõenäoliselt saksa keelest laenatud isanimetus papa (vrd sks kõnek Papa) on eesti murretes eelmistest uuem (kaart 2; EES: 352). Enamasti on see, nagu ka mamma, olnud eestlastele pikka aega rohkem saksik ja linnarahva sõna. Nt Jõh Nied kõik on 'albid, üks kord 'mõisa 'kaevust vett saand, siis on pappa ja 'mamma; Ris (1924) antvärgid ütlevad isa asemel papa. Selle soomekeelne vaste pappa $(<\mathrm{rts}$ pappa) on samuti suhteliselt hiline moesõna (ALFE: 175; SMSA). Läänemeresoome isanimetuste kaardile on soome ja eesti papa levik märgitud vaid atlase kaardistuspunktides (ALFE: 191)2. Eesti keeles tarvitatakse sõna papa isanimetusena tänini ning sellele on lisandunud argikeelne paps (ÕS 2013: 645).

\section{Rindühendid tähenduses 'vanemad'}

Mõlemast lapsevanemast rääkides on üldnimetuse vanemad vms asemel sageli kasutatud isa- ja emanimetust koos, nt Kaa Teab kesse isa-ema laps see veib olla; Ran esäst emäst es pia nemä lugu; Vas imä ni esä 'lätsi †üühhü. Murdekeeles esineb sõnapaar tihti osastava käände vormis, nt Krk esät emät kolksive linu. Sõnapaar memm ja taat oli selles tähenduses üldlevinud Tartu murdes, aga teateid leidub ka mujalt, nt SaLä LNg KJn Vil $\mathrm{jm}$. Saaremaale oli omane emm ning taet (Jaa toet), mis oli levinud kohati ka läänemurdes, nt Vän `taati 'emme. Põhja-Eestis ning mõnikord Tartu murdes on isa-ema kohta öeldud eit ja taat, kuid sagedamini märgib see vanemaealist abielupaari. Võru murdes on vanemaid kutsutud äide-tätä, nt

2 Et ALFE kaart pidi kajastama ametlikke murdenimetusi, esitati selle jaoks eesti keelest isa ja esä variandid. Muud nimetused (papa, att, ätt, taat jt) liigitati kutsumisnimetusteks. Kaardi autor Seppo Suhonen otsustas kuvada mõnes läänemeresoome keeles olevate sõnade leviku kõigi asjaomaste keelte kaardistuspunktides, lisades eesti murdevasted sõnaraamatutest (Wiedemann 1973: 767; EKMS 1: 653; VMS: 174). 
Hargla äide-tätä 'saaja ‘aigu 'ema-isa pulma ajal'. 1947. aastal on sellist sõnapaari kasutatud vaid kutsumisnimetusena, nt Har ku `hõiksi, siss ‘ülti äide ja tätä, muidu imä-esä. Kihnu murrakus kutsuti vanemaid eit ja att, Mulgi murdes ja selle naabruses oli veel XX sajandi algul tüüpiline näńn ja ätt (ätti `nänni, `nänni ätti, ätte `nänne). Nt 1950. aastal ütles Viljandi keelejuht: sii õikab oma emät memmess, isät taadiss, viiekümne aasta iisst õegati ätti- `näńni (EMSUKA).

Omaette paarid moodustavad hilisemad laenud mamma ja papa (papamamma) ning mammi ja papi (papi-mammi), mida umbes XX sajandi keskpaigani on peetud pigem uueks ja peenutsevaks. Nt Lüg pienemalt ütlevad 'mammi ja pappi; Khk papa ning mamma on sakstel, 'meitel on taet ning emm; (1939) nüid papa ning mamma, [varem] taet ning emm; Nõo (1957) vanast üteldi taat ja memm, peenembä inimese ‘ütlivä papa ja mamma. Samas on Pöide keelejuht 1950. aastal väitnud, et esiti üiti papa ja mamma, nüüd on isa ja ema (EMSUKA). Murdeainese põhjal ei ole emanimetus mamma ja isanimetus papa siiski võrdselt ja täiesti samal alal levinud (vt kaart 5). Uusim õigekeelsussõnaraamat esitab papad-mammad stiilimärgendita ning selle kõrval argikeelsed paps ja mamps (ÕS 2013: $521,645)$. Suhteliselt uue rindühendi moodustavad hoidjakeelsed emmeissi (issi-emme), emmed-issid (issid-emmed).

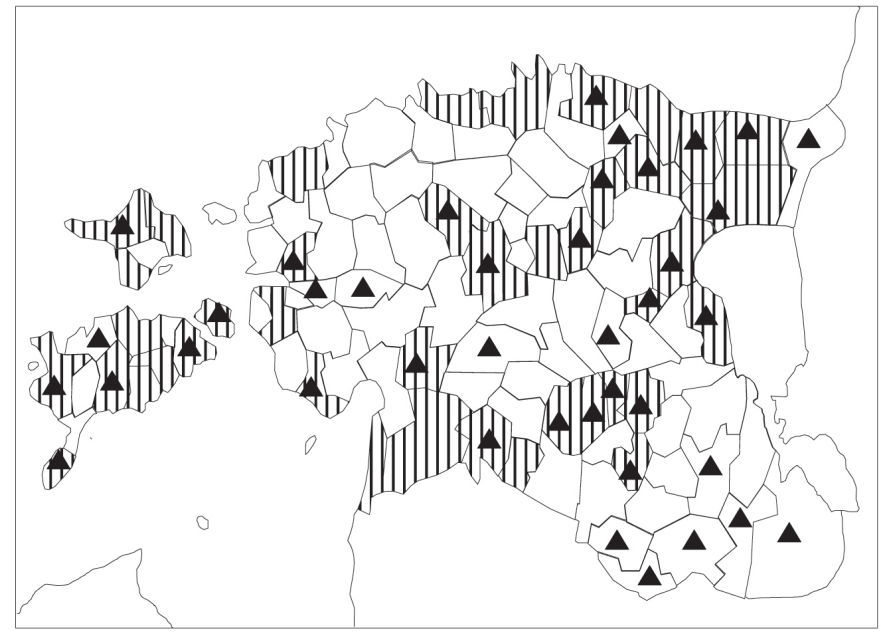

IIIIIIII papa

- mamma

Kaart 5. Papa ja mamma eesti murretes 
Vanemate nimetamine rindühendiga on olnud rahvakeeles väga tavaline. Ühenditest selgub, milliseid nimetusi on korraga kasutatud. Rindühend muutus koos uue põlvkonna kutsumisnimetustega, nt Hargla (1945) nika ’kutse mi äide ja tätä nikagu `surma 'lätsi, egas mi nuid iss kutsu mamma vai papa. Murdekeelne sõnapaar oli nii tüüpiline, et selle järgi võis määrata kõneleja kodukanti. Nt Nõo keelejuht selgitas, et mulgi .. ‘ütlevä näńn ja ätt, aga meie 'ütleme memm ja taat. Peres, kus vanemad olid pärit eri murdealadelt, esines kahesugust kõnepruuki, nt Kambja keelejuht, kelle isa oli mulk, tarvitas nii sõnapaari eit ja taat kui ka näńn ja ätt. Ülaltoodud rindühenditest erinevaid kombinatsioone on kirja pandud vähe, üksikuid näiteid leidub sõnapaaride ema ja taat (Kuu), nänn ja taat (Muh (taet), Hel), nenn ja tätä (I), memm ja at́t (Tor), emm ning papa (Khk) kohta. Tavapärasest hälbiv nimetus võib kajastada nii individuaalseid iseärasusi (nt mujalt tulnud pereliige, naabrite mõju jm) kui ka ühe kutsumisnimetuse muutust.

\section{Tähendusmuutused}

Sageli kutsutakse ema ja isa ka pärast nende jõudmist vanavanema staatusesse endise nimetusega, nt Jõh Mõnel oo vanaema memm [harilikult 'ema']. Kahe põlvkonna isikute sama nimetust on vajaduse korral täpsustatud omadussõnaga, nt Mih kui kaks atti elas, siiss 'üeti vana att ja noor att (EMS I: 490); V11 (1950) noor taet ja vana taet, või on kasutatud vanavanemaid tähistavaid liitsõnu täiendosisega vana-, ell- jt (vt nt Vääri 2013: 72-73, 83-84; ALE 2014: kaardid 86, 87; Brietz 2014: 157, 160-161, 178-179, 181). Enamikus murdeomastes ema ja isa kutsumise nimetustes on praeguseks toimunud tähendusnihe. Ema või isa märkiv tähendus on tasapisi taandunud või kadunud ning neist sõnadest on saanud vastavalt vanaema- või vanaisanimetus, aga laiemalt ka (harilikult vanemaealist) naist või meest tähistav sõna.

Ema hellitusnime eit teatakse tänapäeval rahvaluulest, kuid tavakõnes öeldakse eit harilikult vana naise või (vanemaealise) abikaasa, harva ka vanaema kohta (EKSS 1: 280-281; EMS I: 636-637). Võru murdes esineb samast tüvest pärit ema hellitusnimi (äidi, äide, ääde) hiljem tähenduses 'vanaema' ja 'vana naine'. Endised emanimetused nänn, nann ja moor tähistasid XX sajandil ka mõisteid '(vana)vanaema', '(vanemaealine) abikaasa' ja 'vana naine, eit'. Varasem isanimetus ätt või att tähistas juba 
XX sajandi keskpaiku murdekeeles peamiselt vanaisa ja vana meest, nt Tor (1961) vanast 'üüt vanaisa ikki ätese; Hää (1937) vanad mehed kõik oo ätid. Tänapäeva kirjakeeles märgib ätt väga vana meest (ÕS 2013: 1109). Nimetus taat, mis varem oli küllalt tuntud nii isa ja vanaisa kui ka vana mehe nimetusena (nt VNg taat oli isaisa ehk emaisa; Lüg (1932) 'lapsidelle on isäisä 'taadist), märgib nüüd põhiliselt vana meest, paiguti ka vanaisa. Sõna on murretes üldlevinud (VMS: 474), kuid isanimetusena pole kõikjal tarvitatud (kaart 4; EMSUKA).

Kirjakeeleski hästi tuntud memm ja saarte murdes emanimetusena juurdunud emm esinevad sageli tähenduses 'vanaema, (vanem) naine, abikaasa, perenaine', nt VMr vanaemale 'üeldakse memm; Mar mes ead paksud naeste rahvad oo, need oo memmed; Ran kelläme memm 'olli edevä 'suuga; Khk koes vanad emmed koos, sääl oo ikka palju juttu; Kaa Me oleme eese emmega juba ligi viiskümmend aastat paaris olnd; Muh kellel es ole last, see üiti emmeks (EMS I: 737-738). Uuemaid laensõnu mamma, mammi ja papa, papi on murretes tarvitatud paralleelselt vastavalt tähendustes 'ema' või 'isa', 'vanaema' või 'vanaisa' ja 'abikaasa; vanem naine või mees; perenaine või peremees' (EMS V: 936; EMSUKA). Tänapäeva kirjakeeles esineb mammi peamiselt tähenduses 'mutike, eideke', aga mamma on säilinud ka emanimetusena ning papa ja papi isanimetusena (ÕS 2013: 521, 645).

Lastevanemate nimetuste ülekandumist vanavanematele on põhjendatud peresiseste muutustega põlvkondade vahetumisel: kui täiskasvanud pereliikmed kutsuvad oma ema ja isa edasi endiste nimetustega (nt ema ja isa või memm ja taat), siis laste jaoks on need vanaema ja vanaisa kutsumise nimetused. Tegelikkuses on lugu komplitseeritum. Kutsumisnimetuste valikut mõjutavad mitmesugused tegurid, nagu kohalikud traditsioonid, noorte vanemate päritolu (endine kodumurrak), kas mitu põlvkonda elab koos või elavad vanavanemad omaette, mitu vanavanemat lastel on, kui ema ja isa õdedel-vendadel on lapsed, kuidas need vanavanemaid kutsuvad jm (vt ka Neetar 1997). Murdematerjali analüüs näitab, et endine isa- või emanimetus hakkas vanavanemat tähistama seejärel, kui noorema põlvkonna lapsevanema nimetus muutus. Kahe põlvkonna vanemate erineva nimetuse puhul polnud enam vaja kasutada liitsõnu täiendosisega vana- vms, nt IisR (1977) kui oma isa `kutsuti pappast, siis suurisa oli isa; Nõo kos papa ja mamma `olli, sääl üteldi vanaesäd esäss ja vanaemäd emäss (EMS V: 936). Pajusalu (1996: 121) andmetel nimetati 
1990-ndatel ema hoidjakeeles emme, emps, empsu, ning vanaema kutsuti mamma ja memme. Samasugust tendentsi on täheldatud soomekeelsete kutsumisnimetuste vaheldumises (Nirvi 1952: 131-132). Eesti noorema põlvkonna massilisel kirjakeelele üleminekul (eriti XX sajandi 2. poolel) loobuti murdelistest isa- ja emanimetustest, misjärel need jäid tavaliselt vanema põlvkonna kutsumise nimetusteks. Kui lastel oli mitu ühest soost vanavanemat, varieerusid nimetused mitmeti, nt Har imäimä oĺl unuäidi ja esäimä oĺl vanaimä; minu Lõuna-Tartumaa vanaemadest oli üks mamma ja teine mammi, ainukest vanaisa nimetasime aga vanaisaks.

\section{Laste- ja hoidjakeel kutsumisnimetuste allikana}

Väikesed lapsed jäljendavad kuuldut, hääldades algul üksikuid silpe ning moodustavad neist seejärel reduplikatsiooni teel pikemaid sõnu. Euroopa keelte murretes esinevaid lastevanemate nimetusi võrreldes on tõdetud, et väga ulatuslikult esinevad neis konsonandid $p, b, t, d, m, n$, moodustades vokaaliga $a$ silpe $p a-, b a-, t a-, m a-, n a-$ ja $a p-, a b-, a t-, a m-, a n-$ (nt Brietz 2014: 111-112). Indoeuroopa keeltes prevaleerivad meessugulaste kutsumise nimetustes klusiilidega silbid ja naissugulaste nimetustes nasaalidega silbid, ehkki leidub ka vastupidiseid näiteid (Buck 1949: 93-94). Ema, vanaema või mõnda muud naissugulast tähistavad paljudes keeltes sõnad, mis arvatakse põhinevat lastekeelsel silbil $m a$ - või $n a-$, sh näiteks sanskriti nanā ja ladina mamma 'ema' (kreeka $\mu \alpha \dot{\alpha} \mu \alpha, \mu \alpha ́ \alpha \mu \eta, \mu \alpha \mu \mu i \alpha$ 'ema, vanaema' ja vóvva 'tädi') (Pokorny I: 694; Brietz 2014: 166-168). Paljud meessugulasi (isa, vanaisa, onu jt) ning vana meest märkivad sõnad koosnevad silbi $p a$ - või ta- reduplikatsioonist, vrd nt sanskriti tâta, tata, kreeka $\pi \dot{\alpha} \pi \pi \alpha$ ja $\tau \dot{\alpha} \tau \alpha, \tau \dot{\varepsilon} \tau \tau \alpha$, ladina pāpa ja tata (Pokorny I: 789, 1056; Brietz 2014: 118-121, 127-130). Indoeuroopa lastekeelne *atta arvatakse olevat lähtekujuks vanadele isanimetustele, nagu kreeka ó $\tau \tau \alpha$, ladina ja gooti atta, algslaavi otbcb (Pokorny I: 71; Brietz 2014: 117).

Samasuguse konstruktsiooniga vanemanimetusi leidub eesti keeles ja teistes läänemeresoome keeltes. Osal neist, nagu papa, mamma, maama, memm, nann, on tuvastatud laenuline päritolu (siia võiks ehk lisada tata/ tätä ja att/ätt), mõnes sõnas, nagu nänn, on oletatud läänemeresoome või varasemat sugulaskeelte omatüve. Paljude teiste Euroopa keelte sarnaste murdesõnade puhul ei ole samuti tõestatud omavahelisi laenusuhteid, vaid viidatakse võimalusele, et need on tekkinud kohaliku lastekeele alusel. 
Lastekeelsetel häälitsustel baseeruvad isa, ema jt sugulaste kutsumise nimetused võivad loomulikult olla tekkinud üksteisest sõltumatult maailma eri paikades, ent ikkagi jääb õhku küsimus, miks lapsed on eelistanud ema nimetamisel nasaalidega ja isa nimetamisel klusiilidega silpe.

Eesti lastekeeles on esmalt rohkem selliseid ühesilbilisi sõnu, millel muutevormides on lühikese geminaadiga kahesilbiline kuju, kusjuures eelistatakse trohheilist kõnetakti (Pajusalu 2001: 83; Argus 2008: 30 jj). Niisugused on ka nt emm, memm, nänn, nann, nenn, ätt, att. Lastekeel pole aga valdavalt laste looming, vaid tekkinud suures osas vanemate, hooldajate ja ümbruskonna kõnepruugis (vt nt Mägiste 1924: 3). Eesti lapsele suunatud kõnet ehk hoidjakeelt ${ }^{3}$ iseloomustab samuti trohheiline kõnetakt, sageli pikendatakse konsonante ja eelistatakse lühikese geminaadiga kahesilbilisi sõnu (Kõrgesaar 2009: 34). Hoidjakeelest tingitud erijoontele, sh murdeerinevuste ja keelekontaktide mõjule eesti laste sõnavaras on osutanud ka Karl Pajusalu (1996: 117). Viimase poole sajandi jooksul järjest enam levinud nimetused emme ja issi on tüüpilised hoidjakeele sõnad. Sisulist ja vormilist külge silmas pidades on need liigitatud tüvemuutuslikeks deminutiivideks (Kõrgesaar 2009: 36). Murretes leiduvad vaid üksikud näited nimetuse emme kasutuse kohta ning levikut arvestades võib neist mõne aluseks olla murdesõna emm g emme (vt osa 2). Muuttüübilt kuuluvad nii emm kui ka emme tänapäeval eesti lastel kõige produktiivsemate hulka (vt Argus 2008: 37-38).

Õigekeelsussõnaraamatus esitatakse sõna emme esimest korda 1976. aastal (ÕS 1976) ning issi järgmises uues väljaandes (ÕS 1999), mõlemad märgendiga „lastekeelne“. Enda kogemustest mäletan, et 1960-ndate algupoolel tarvitati mõnes peres lastega suheldes sõna emme, aga nimetust issi ma tollal ei kuulnud, kuid 1970-ndate lõpus olid mõlemad sõnad vähemalt lasteaias käibel. Kadri Videri (1996: 130) praktilise uuringu käigus selgus, et XX sajandi lõpul olid eesti laste seas emme ja issi juba levinumad kui ema ja isa. Tänapäeva eesti kõnekeelt jälgides tundub, et emme ja issi on kujunenud üldkeelseteks moesõnadeks, mida kasutatakse laiemalt kui pelgalt suhtluses väikelastega või pereringis. Vanemaid nimetatakse sageli nõnda ka siis, kui laps (või lapsed) on keele omandanud, jõudnud kooliikka ja edaspidigi ning neid sõnu võib kuulda isegi täiskasvanute omavahelises suhtluses. Väikelastel ei ole ema ja isa keerulisem öelda kui emme ja issi, kõik need on kahesilbilise kõnetaktiga sõnad, kus vokaal ja konsonant

3 Terminite sisust täpsemalt vt nt Argus 2008: 14; Kõrgesaar, Kapanen 2015: 184. 
vahelduvad $^{4}$. Nt lõunaeesti lastekeeles on $3 / 5$ sõnadest struktuuriga (C) VCV või (C)VCCV (Pajusalu 2001: 82-83). Miks siis tavatsetakse lapsega kõnelda moonutatud keeles? Selleks peetakse emotsionaalseid põhjusi, nimelt püüab täiskasvanu ebakorrektse keelekasutusega näida lapse sarnane, soovides seeläbi olla lapse poolt nii-öelda omaks tunnistatud (vt nt Jocić 1978: 159). Nagu märkis juba Heikki Ojansuu (1905: 54), on hoidjakeeles tekkinud sugulusnimetustel tendents kujuneda hüüd- ja meelitusnimedeks ning hiljem muutuda keele üldvaraks.

Tallinna keskkooliõpilastel olid 1989. aastal ema ja isa meelitus- või hellitusnimetustena tüdrukute hulgas levinud emm, emme ja iss, issi, aga poistel empsu ja paps (vt Loog 1991: 60-61, 64-65). Sõnad emps, empsel, mamma, mammi, mamps, mam(p)sel ja paps, papi, papa esinesid gümnasistide omavahelises suhtluses stiililt neutraalsena. Murretes tuntud nimetustest kasutati veel ema kohta sõnu eit, memm, moor ja isa kohta taat, ätt, mille puhul on mingil määral võinud mõju avaldada arhailise stiili taotlus või kõneleja murdetaust (Loog 1991: 61). Kui jutt ei olnud pereliikmetest, tarvitati neidsamu sõnu pejoratiivses tähenduses. Näiteks tütarlast nimetati eit, emme, mammi, mutt vms, väljendamaks halvustavat suhtumist, ebameeldiva naisterahva kohta öeldi eit, mammi, memm, moor, mutt vms (Loog 1991: 20-21, 56-57). Släng on siiski vaid teatud seltskonnas aktsepteeritud kõnepruuk, mida igas situatsioonis ei kasutata. Kõnetussõnad, millega pöördutakse isa ja ema või ka teiste sugulaste poole, on paljudel juhtudel individuaalsed ning erinevad isegi pereti. Võõramaid inimesi kõnetatakse enamasti neutraalsete nimetustega.

\section{Kokkuvõte}

Eesti murretes esinevate ema kutsumise nimetuste nänn, nann, eit, äidi (jt variandid) ning isanimetuste tätä, ätt ja att puhul ilmnevad selged regionaalsed erinevused. Seevastu emanimetus memm ja isanimetus taat on üsna laialt on levinud. Põhiliselt Saaremaale murdeomase emm kohta on üksiknäiteid ka teistest murretest. Suhteliselt hiliseid laene mamma ja papa on kasutatud murdekeeles tihti kõrvuti varasemate nimetustega ning kaua aega peeti neid peenutsevaks. Mõistet 'lastevanemad' väljendatakse

${ }^{4} \mathrm{Nt}$ soome murretes on isa ( $\mathrm{sm} i s \ddot{\text { }}$ ) hellitusnimetuseks $i s u$ ja samast tüvest lähtuvad tuletised isuka, isuli, isuri, isuska, isykkä, isäkkä; Kallivere murdest kirja pandud rahvalaulus esineb rindühend isut ja emyt 'isa ja ema' (SMS 2: 8; SMS 4: 892-893). 
rahvakeeles sageli ema- ja isanimetusest koosneva rindühendiga. Eri murdealadel on kasutatud ühendeid nänn ja ätt, eit ja taat, memm ja taat, Saaremaal emm ning taet, Kihnus eit ja att. Rindühendeid mamma-papa, papi-mammi jms iseloomustab hajalevik suures osas eesti murretest.

$\mathrm{XX}$ sajandi jooksul on eesti murretes osa isa ja ema kutsumise nimetusi vahetunud, kusjuures varasemate nimetuste tähendus on muutunud. Tähendusmuutusi 'ema' > 'vanaema' ja 'isa' > 'vanaisa' võib seostada uute ema- ja isanimetuste käibelevõtuga. Samas on tasapisi toimunud tähenduse laienemine mõistetele 'majaperenaine või -peremees; abikaasa; vana naine või mees'. Laensõna võib olla juba laenatud mitmetähenduslikuna (nt moor < erts mor 'ema, naine, abikaasa'). Eri nimetuste aluseks on sageli olnud (vana)vanema murdetaust või tema kodukoha, pere jt lähikondsete traditsioon. Mõne uue nimetuse (nt mamma ja papa) eelistus oli esialgu vähemalt osaliselt tingitud prestiižist, taotlusest sarnaneda jõukate ning haritud inimestega.

Lastevanemate nimetused, mis paljudes keeltes sarnanevad üksteisega struktuurilt ja häälikkoosseisult, arvatakse baseeruvat laste- või hoidjakeelsetel sõnadel. Etümoloogid ei pea kõiki maailma eri nurkades esinevaid sarnaseid sõnu laenusuhtes olevaiks, vaid usuvad, et neid on tekkinud eri keeltes ka omaalgatuslikult laste lalina alusel. Euroopa keeltes leiduvate ema- ja isanimetustega sarnanevad näiteks eesti vasted nann, nänn, memm, mamma, maama, papa, tata, tätä, ätt, att, taat. Enamik neist on eesti keeles laensõnad. Nimetused emme ja issi, millest tänapäeval on kujunenud üldkeele sõnad, pärinevad XX sajandi 2. poole eesti hoidjakeelest. Vanemate kutsumise nimetused on üldiselt küllalt perekesksed, mistõttu võõrastega vesteldes on pigem eelistatud neutraalseid, nn ametlikke kõnetussõnu.

Eesti sõnade analüüs võrrelduna sugulaskeelte ja kontaktkeelte vastetega näitas, et küllalt pika ajaperioodi jooksul murretes kasutatud nimetuste jagamine ametlikeks ja mitteametlikeks on mõneti komplitseeritud. Selle tulemusena puudub ALE ja ALFE kaartidelt rida eesti sõnu, mis naaberkeeltes on esindatud. Nagu siinsetelt kaartidelt näha, on osa neist kuulunud kindlalt mingi murdeala aktiivse sõnavara hulka. Koos teiste keelte materjaliga kaardistatuna pakuks kahtlemata rohkem huvi vähemalt teatud tüvega sõnade levik nii ühe (nt ema) kui ka mitme sugulase nimetusena (nt naissoost sugulased). Sõnade häälikulist külge käesolevas kirjutises ei analüüsitud, kuid väärib tähelepanu, et mõnest nimetusest esineb nii ees- kui ka tagavokaalseid variante (nänn ja nann, ätt ja att, tätä ja tata). 
Kas variatiivsus seostub sõnade päritoluga või on tegemist lastekeele omapärase ilminguga või mingi muu põhjusega, vajab omaette uurimist.

\section{Kirjandus}

ALE 1976 = Antonius Weijnen, Joep Kruijsen, et al. Atlas Linguarum Europae (ALE). Premier questionnaire: onomasiologie, vocabulaire, fondamental. Assen / Amsterdam: Van Gorcum.

ALE 2014 = Cartes linguistiques Européennes. ALE, Volume I, huitième fascicule. Cartes. (=Academia Română. Institutu de Linguistică ,Iorgu Iordan - Al. Rosetti“). Bucharest: Editura Universităţii din Bucureşti.

$\mathbf{A L F E}=$ Atlas Linguarum Fennicarum. Itämerensuomalainen kielikartasto. Läänemeresoome keeleatlas. Ostseefinnischer Sprachatlas. Лингвистический атлас прибалтийско-финских языков. ALFE 2, 2007. Päätoim. Tuomo Tuomi. 2. osan vastaava toimittaja Tiit-Rein Viitso. Toimitus: Anneli Hänninen, Arvo Laanest, Helmi Neetar, Vilja Oja, Seppo Suhonen, Ulla Vanhatalo, Tiit-Rein Viitso, Tuomo Tuomi, Nina Zaitseva. (= Suomalaisen Kirjallisuuden Seuran Toimituksia 800. Kotimaisten kielten tutkimuskeskuksen julkaisuja 118.) Helsinki: Suomalaisen Kirjallisuuden Seura, Kotimaisten kielten tutkimuskeskus.

Argus, Reili 2008. Eesti keele muutemorfoloogia omandamine. (= Tallinna Ülikooli humanitaarteaduste dissertatsioonid 19.) Tallinn: Tallinna Ülikooli Kirjastus.

Ariste, Paul 1933. Eesti-rootsi laensõnad eesti keeles. (= Acta et Commentationes Universitatis Tartuensis B XXIX3.) Tartu.

Ariste, Paul 1937. Mõningaid alamsaksa laensõnu. - Eesti Keel 5, 132-140.

Ariste, Paul 2010. Sõnalaenulõbu. Koost. Peeter Olesk. Toim. Iti Vanamölder. (= Eesti mõttelugu 93.) Tartu: Ilmamaa.

Brietz, Birgit 2014. QI: 455 Père, отец, father, Vater, padre, papá. QI: 465 Grand-père, дед (дедушка), grandfather, Grossvater, abuelo, nonno. QI: 467 Grand-mère, бабка (бабушка), grandmother, Grossmutter, abuela, nonna. - Atlas Linguarum Europae (ALE), Volume I, huitième fascicule. Commentaires. (= Academia Română. Institutu de Linguistică „Iorgu Iordan - Al. Rosetti“). Bucharest: Editura Universităţii din Bucureşti, 109-198.

Buck, Carl Darling 1949. A Dictionary of Selected Synonyms in the Principal Indo-European Languages. A Contribution to the History of Ideas. Chicago, Illinois: The University of Chicago Press.

Danell, Gideon 1951. Ordbok över Nuckömålet. (= Estlandssvenskarnas folkliga kultur 2. Skrifter utgivna av Kungl. Gustav Adolfs Akademien 27.) Uppsala. 
EES = Iris Metsmägi, Meeli Sedrik, Sven-Erik Soosaar 2012. Eesti etümoloogiasõnaraamat. Eesti Keele Instituut. Tallinn: Eesti Keele Sihtasutus.

EEW = Julius Mägiste 1982-1983. Estnisches etymologisches Wörterbuch. I-XII. Helsinki: Finnisch-Ugrische Gesellschaft.

EKMS = Andrus Saareste. Eesti keele mõisteline sõnaraamat. 1, 1958. Stockholm: Vaba Eesti.

EKSS $=$ Eesti keele seletav sõnaraamat. 1-6, 2009. „Eesti kirjakeele seletussõnaraamatu“ 2., täiend. ja parand. tr. Toim. Margit Langemets, Mai Tiits, Tiia Valdre, Leidi Veskis, Ülle Viks, Piret Voll. Eesti Keele Instituut. Tallinn: Eesti Keele Sihtasutus. http://www.eki.ee/dict/ekss/.

EMS $=$ Eesti murrete sõnaraamat. I-VI, 1994-2016. Eesti Teaduste Akadeemia Eesti Keele Instituut. Tallinn: Eesti Keele Instituut, Eesti Keele Sihtasutus. http://www.eki.ee/dict/ems/; http://www.eki.ee/dict/ems/ems.html.

Jocić, Mirjana 1978. Adaption in Adult Speech during Communication with Children. - The Development of Communication, by Natalie Waterson and Catherine Snow. London: John Wiley \& Son Ltd, 159-171.

Kluge, Friedrich 2002. Etymologisches Wörterbuch der deutschen Sprache. 24., durchgesehene und erweiterte Auflage, bearbeitet von Elmar Seebold. Berlin - New York: Walter de Gruyter.

Kõrgesaar, Helen 2009. Hoidjakeelele omastest joontest. - Oma Keel 2, 28 -37. Kõrgesaar, Helen, Airi Kapanen 2015. Kui lapsega ei räägi üksnes ema: valik termineid eesti laste- ja hoidjakeele kohta. - Eesti Rakenduslingvistika Ühingu aastaraamat 11. Toim. Helle Metslang, Margit Langemets, MariaMaren Sepper. Tallinn: Eesti Rakenduslingvistika Ühing, 177-187. http://dx.doi.org/10.5128/ERYa11.11.

Lehmann, Winfred Philipp 1986. A Gothic Etymological Dictionary. Leiden: Brill.

Loog, Mai 1991. Esimene eesti slängi sõnaraamat. Tallinn: Mai Loog.

Must, Mari 2000. Vene laensõnad eesti murretes. Tallinn: Eesti Keele Sihtasutus. Mägiste, Julius 1924. Paar sõna lastekeelest. - Eesti Keel 1, 1-9.

Neetar, Helmi 1997. The way Estonian children addressed their (grand)parents. Book of Abstracts. 2nd International Congress of Dialectologists \& Geolinguists. Amsterdam, the Netherlands July 28 - August 1, 1997. Amsterdam, 101.

Nirvi, Ruben Erik 1952. Synonyymitutkimuksia sukulaisnimistön alalta. (= Suomi 106: 1.) Helsinki: Suomalaisen Kirjallisuuden Seura.

OFSF $=$ Ordbok över Finlands svenska folkmål. IV (kyssa - och), 2007. Red.

Peter Slotte. (= Forskningscentralen för de inhemska språken, Skrifter 1.)

Helsingfors: Svenska litteratursällskapet i Finland, Forskningscentralen för de inhemska språken.

Ojansuu, Heikki 1905. Pieniä lisiä astevaihteluoppiin. - Virittäjä 9 (1), 54-55. 
Pajusalu, Karl 1996. Eesti hoidekeele kujunemine. - Suomalaisten omaksumista tutkimassa. Toim. Kirsti Toiviainen. (= Turun Yliopiston suomalaisen ja yleisen kielitieteen laitoksen julkaisuja 53.) Turku: Turun yliopisto, $117-124$.

Pajusalu, Karl 2001. Baby talk as a sophisticated register: a phonological analysis of South Estonian. - Psychology of Language and Communication 5 (2), 81-92.

Pajusalu, Karl 2010. Äidin nimityksiä viron murteissa. - Sanoista kirjakieliin. Juhlakirja Kaisa Häkkiselle 17. marraskuuta 2010. (= SuomalaisUgrilaisen Seuran Toimituksia 259.) Helsinki: Suomalais-Ugrilainen Seura, 329-334.

Pokorny, Julius 2002. Indogermanisches etymologisches Wörterbuch. I-II. 4. Auflage. Tübingen-Basel: Francke.

Räsänen, Martti 1969. Versuch eines etymologischen Wörterbuchs der Türksprachen. (= Lexica Societatis Fenno-Ugricae XVII.) Helsinki: Suomalais-Ugrilainen Seura.

Rätsep, Huno 2009. Mul kogu küla sugulasi täis. - Oma Keel 1, 21-33. http:// www.emakeeleselts.ee/omakeel/2009_1/OK_2009-1_03.pdf.

Saareste, Albert 1924. Leksikaalseist vahekordadest eesti murretes. I. Analüüs 60 kaardi ja 1 skeemiga. Résumé: Du sectionnement lexicologique dans les patois estoniens. I. Analyse avec 60 cartes et 1 esquisse schématique (= Acta et Commentationes Universitatis Dorpatensis. B VI, 1.) Tartu.

SKES = Erkki Itkonen, Yrjö H. Toivonen, Aulis J. Joki 1955-1981. Suomen kielen etymologinen sanakirja. I-VII. (= Lexica Societatis Fenno-Ugricae XII, 2. Tutkimuslaitos „Suomen Suvun“ julkaisuja III). Helsinki: SuomalaisUgrilainen Seura.

SMS = Suomen murteiden sanakirja. 2, 1988. 4, 1994. (= Kotimaisten kielten tutkimuskeskuksen julkaisuja 36.) Helsinki: Kotimaisten kielten tutkimuskeskus, Valtion painatuskeskus. http://kaino.kotus.fi/sms/.

SSA = Suomen sanojen alkuperä. Etymologinen sanakirja. 1-3, 1992-2000. Päätoim. Erkki Itkonen, Ulla-Maija Kulonen. (= Suomalaisen Kirjallisuuden Seuran toimituksia 556. Kotimaisten kielten tutkimuskeskuksen julkaisuja 62.) Helsinki: Suomalaisen Kirjallisuuden Seura, Kotimaisten kielten tutkimuskeskus.

Vider, Kadri 1996. 2-3-aastaste eesti laste sõnavara. - Suomalaisten omaksumista tutkimassa. Toim. Kirsti Toiviainen. (= Turun Yliopiston suomalaisen ja yleisen kielitieteen laitoksen julkaisuja 53.) Turku: Turun yliopisto, $125-137$.

VMS = Väike murdesõnastik. II, 1989. Eesti NSV Teaduste Akadeemia. Keele ja Kirjanduse Instituut. Toim. Valdek Pall. Koost. Anu Haak, Evi Juhkam, 
Marja Kallasmaa, Ann Kask, Ellen Niit, Piret Norvik, Vilja Oja, Aldi Sepp, Jaak Simm, Jüri Viikberg. Tallinn: Valgus. www.eki.ee/dict/vms/. Vääri, Eduard 2013 (1953). Sugulusalane sõnavara läänemeresoome keeltes. Toim. Urmas Sutrop. Eesti Keele Instituut, Tartu Ülikool. (= Töid antropoloogilise ja etnolingvistika vallast 8.) Tallinn: Eesti Keele Sihtasutus.

Wiedemann, Ferdinand Johann 1973 (1893). Eesti-saksa sõnaraamat. Neljas, muutmata trükk teisest, Jakob Hurda redigeeritud väljaandest. Tallinn: Valgus.

ÕS 1976 = Õigekeelsussõnaraamat. Toim. Rein Kull, Erich Raiet. Eesti NSV Teaduste Akadeemia Keele ja Kirjanduse Instituut. Tallinn: Valgus. http:// www.eki.ee/cgi-bin/qs76.

ÕS $1999=$ Eesti keele sõnaraamat ÕS 1999. Toim. Tiiu Erelt. Koost. Tiina

Leemets, Sirje Mäearu, Maire Raadik, Tiiu Erelt. Eesti Keele Instituut. Tallinn: Eesti Keele Sihtasutus.

ÕS 2013 = Eesti õigekeelsussõnaraamat ÕS 2013. Toim. Maire Raadik. Koost. Tiiu Erelt, Tiina Leemets, Sirje Mäearu, Maire Raadik. Eesti Keele Instituut. Tallinn: Eesti Keele Sihtasutus. http://www.eki.ee/dict/qs/.

\section{Sõnavarakogud}

EMSUKA $=$ Eesti murrete ja soome-ugri keelte arhiiv Tallinnas Eesti Keele Instituudis.

SMSA $=$ Soome murrete sõnaarhiiv Helsingis Kodumaa Keelte Keskuses. 


\title{
Estonian vernacular words for 'mother' and 'father'
}

\author{
VILJA OJA
}

In 20th-century Estonian dialects, in familiar informal speech, the words nänn, nann, eit, äidi (and other variants), emm, memm, mamma (mammi), moor, and mutt (muti) were used as synonyms for the standard ema 'mother', while the words ätt, att, taat, tata, tätä, and papa (papi) were used as synonyms for the standard isa 'father'. The oldest of these are eit, emm, nänn 'mother' and ätt, taat 'father' along with other variants of these stems. Alongside the older words, also used in 20th-century Estonian were the relatively recent German loans mamma and papa, which were regarded as snobbish until roughly the middle of the century. In the 1960s, the Estonian caregiver speech forms emme 'mum' < ema and a bit later issi 'dad' < isa began to grow in popularity. Today, these have evolved into nearly standard terms of endearment. The informal names are typically used only family-internally, and therefore neutral, so-called formal terms of address are preferred when talking to strangers.

The concept of 'parents' was expressed in the vernacular typically by a coordinate structure, such as eit ja taat, memm ja taat, mamma-papa etc., literally 'mother and father'. Some of these were used in particular dialect regions, e.g. nänn ja ätt in the Mulgi dialect, emm ning taet on the island of Saaremaa, eit ja att on Kihnu. The meaning shifts 'mother' > 'grandmother' and 'father' > 'grandfather' are connected with the introduction of new words denoting mother and father. The choice of names has also been influenced by the dialect background of the parent or grandparent or the tradition of his/her hometown/region and family. In addition, the meaning of these words has expanded to also cover notions such as 'lady/man of the house; spouse; old woman/man'. In some cases, polysemous foreign words are borrowed with the polysemy preserved, e.g. moor $<$ Estonian Swedish mor 'mother; woman; wife'.

In Estonian, we find the same structures as in many Indo-European and Turkic languages: words for 'father' are often formed from syllables containing the plosive $p(b)$ or $t(d)$ and the vowel $a$, while words for 'father' have the nasal $m$ or $n$ instead of the plosive. Some of the words used in Estonian are borrowings, although not all of their origins are clear. Names for parents which resemble one another in structure and phonemic composition in numerous languages not in contact with one another are considered to derive from local child or caregiver language forms. The analysis of Estonian words for 'mother' and 'father' com- 
pared to the equivalents in related and contact languages indicates that the division of longtime dialect words into the categories of "formal" and "informal" is quite complicated and may eliminate interesting opportunities for comparison.

Keywords: words for parents, meaning changes, child and caregiver speech, Estonian dialects

\section{Vilja Oja}

eesti keele ajaloo, murrete ja soome-ugri keelte osakond

Eesti Keele Instituut

Roosikrantsi 6

10119 Tallinn

Vilja.Oja@eki.ee 